\title{
La Evaluación Docente en Jaque: La Visión de los Funcionarios Universitarios
}

\author{
Teacher Evaluation in a Tight Spot: The Vision of University \\ Administrators
}

\author{
María Isabel Arbesú García 1* \\ José María García Garduño ${ }^{2}$ \\ ${ }^{1}$ Universidad Autónoma Metropolitana, Unidad Xochimilco \\ ${ }^{2}$ Universidad Autónoma de la Ciudad de México
}

\begin{abstract}
El propósito de este artículo fue identificar las opiniones de los funcionarios universitarios de una institución pública mexicana, acerca de la evaluación docente. A partir de una investigación cualitativa se retomó la propuesta teórico-metodológica de las representaciones sociales, ya que ésta permite detectar esquemas subjetivos de percepción, de valoración y acción de los sujetos. La población participante fueron diez funcionarios: la Rectora de la Universidad y nueve funcionarios de la División de Diseño, a saber: el director de la División de Ciencias y Artes para el Diseño, los cuatro jefes de departamento que la integran y los cuatro coordinadores de las licenciaturas. Se realizaron entrevistas en profundidad con cada uno de los funcionarios. Se sistematizó y analizó la información empírica, para ello se utilizó el análisis de contenido, destinado a formular, a partir de ciertos de los datos, inferencias reproducibles y válidas, Los resultados indican que los funcionarios universitarias no tienen una conceptualización clara sobre la evaluación docente, más bien han logrado identificar los distintos usos que a ésta se le atribuyen entre los cuales señalan: que la evaluación docente es sinónimo de los cuestionarios estudiantiles, una rutina burocrática, parte de una remuneración económica, evaluación que es rechazada por los alumnos. Representaciones que en su gran mayoría los funcionarios están en desacuerdo, a pesar de que son autoridades responsables de dirigir las políticas de evaluación en esta universidad.
\end{abstract}

Palabras clave: Funcionarios universitarios, Evaluación del profesorado, Evaluación sumativa, Representaciones sociales.

The purpose of this paper was to identify the opinions of administrators of a Mexican public university about the evaluation of teaching. Based on a qualitative research design Social Representation theoretical-methodological approach was employed. Social representation approach was used in order to pinpoint subjective schemes of perception, value and action of subjects of the study. Participated in this study 10 university administrators as follows: one university president, one dean, four chairpersons, and four major coordinators of the Sciences and Art of Design Division. Empirical data was analyzed through content analysis in order to produced, based on data, valid consistent inferences. Results indicated that university administrators have not a clear conception of what teaching evaluation is. Rather they are inclined to define teaching evaluation associated to their multiple uses: teaching evaluation as student rating questionnaire; as bureaucratic routine, as salary bonus. Administrators stated that students reject teaching evaluation. University administration social representations also indicate that they disagree with teaching evaluation, in spite that they are in charge of implementing it at the institution.

Keywords: University administrator, Teaching evaluation, Summative evaluation, Social representations.

*Contacto: isabel.arbesu@gmail.com

issn: 1989-0397

www.rinace.net/riee/

https://revistas.uam.es/riee
Recibido: $\quad 17$ de agosto de 2017

$1^{\text {a }}$ Evaluación: 19 de septiembre de 2017

Aceptado: $\quad 6$ de octubre de 2017 


\section{Introducción}

La evaluación de los docentes por sus estudiantes es una práctica generalizada. En el medio internacional, la mayoría de las instituciones universitarias han adoptado esta práctica. El instrumento más empleado para llevar a cabo esta tarea es un cuestionario en el cual los estudiantes vierten su opinión sobre el desempeño de su profesor. Esta política de rendición de cuentas ha sido cuestionada en varias latitudes Latinoamericanas. México no es la excepción (García Garduño, 2014).

La evaluación de la docencia universitaria en América Latina, y probablemente en Iberoamérica comenzó en México a finales de la década de los 60 y principios de la de los 70 en la Universidad Iberoamericana, la UNAM y el Instituto de Estudios Superiores de Monterrey (García Garduño, 2000). Durante la década de los 80 algunas otras instituciones universitarias mexicanas, públicas adoptaron esta práctica. En estos periodos, la evaluación docente se llevaba a cabo con fines formativos. En general, los resultados no tenían consecuencias en la situación laboral o salarial de los docentes.

El panorama cambió a partir de principios de la década de los 90 cuando se crearon los programas de estímulos al desempeño (Rueda, Luna, García Cabrero y Loredo, 2010). Bajo ese rubro, los resultados de la evaluación docente afectan las percepciones salariales de los profesores. Esto ha tenido un efecto perverso en los fines de la evaluación. Los docentes intentan conseguir mejores evaluaciones de los estudiantes a cambio de mejores notas o calificaciones (García Garduño, 2008; Silva, 2009). Ibarra y Porter (2007) señalan que la introducción de la variable económica en la política de evaluación docente provocó que las finalidades sustantivas de la evaluación se desplazaran por consecuencias materiales, lo cual produjo confusión sobre las motivaciones del trabajo académico.

Rueda et al. (2010) llevaron a cabo una investigación a nivel nacional sobre la situación de la evaluación docente en las instituciones de educación superior nacionales. Los autores encontraron que a pesar de que las instituciones universitarias refieren como primera intención la de mejorar la función docente, los fines de la evaluación se encuentran vinculados fundamentalmente con propósitos administrativos; en el 81\% de las universidades, la evaluación de la docencia forma parte de programas de estímulo al desempeño docente y la acreditación de programas de licenciatura y posgrado.

Parece ser que los fines de la evaluación preminentemente administrativos, sobre los de mejora de la calidad ha tenido efectos negativos tanto en los profesores como en los estudiantes. Al respecto Silva (2009) estudió la percepción de los estudiantes y profesores de una universidad estatal del norte del país. El autor señala que la planta docente se siente presionada porque cuando obtienen puntajes abajo del promedio en el cuestionario de opinión les impide participar en los programas de estímulos. El profesorado lo equipara a una espada de Damocles que cualquier estudiante puede calificarlo mal, sin una justificación de peso.

Por otra parte, en relación con los estudiantes, Silva señala que se resisten a participar en el llenado electrónico de la encuesta. Los estudiantes la encuentran monótona y con un número excesivo de reactivos. García Garduño (2014), en una investigación con estudiantes de ciencias sociales y humanidades de una universidad estatal mexicana del centro del país, encontró que para los estudiantes la evaluación docente no tiene ninguna 
utilidad, es aburrida de responder; algunos estudiantes la emplean para tomar revancha de sus profesores y de acuerdo con la opinión de este grupo, los cuestionarios no son válidos para medir el desempeño docente. Arbesú, Moreno, Comas y Contreras (en prensa), realizaron una investigación en una universidad pública de la ciudad de México para conocer la opinión de los estudiantes sobre la evaluación docente. Los resultados indican que para los alumnos la evaluación no tiene utilidad, se emplea como un trámite burocrático, como algo polémico y contradictorio, ya que aunque ellos evalúen a sus profesores, éstos no toman en cuenta sus opiniones y todo sigue igual. Asimismo, opinan que la evaluación es una pérdida de tiempo y de dinero, una mera rendición de cuentas.

Como se ha visto, la investigación realizada informa sobre el empleo de los cuestionarios en las instituciones de educación superior y sobre las percepciones de los profesores y estudiantes. Sobre lo que opinan las autoridades o funcionarios universitarios se han realizado pocos estudios en el medio latinoamericano. Entre esas pocas destaca la realizada por Zúñiga y Joipa (2007) sobre la opinión de la evaluación docente por parte de las autoridades de varias universidades chilenas. Los autores entrevistaron a vicerrectores académicos y decanos. Los hallazgos muestran que el uso que generalmente se le da a la evaluación docente consiste en otorgar un estímulo a la excelencia o sancionar al profesor y cancelar su contrato laboral con la institución. Los vicerrectores comentan que la mayor parte de las veces no hay cambios sustantivos por parte de los docentes, a partir de la evaluación que realizan los estudiantes de sus profesores, y que en realidad no hay un sistema de evaluación de la docencia, porque el único mecanismo que existe es una encuesta de opinión estudiantil.

Coloma (2010) realizó en Perú, una investigación a nivel licenciatura que tuvo como finalidad conocer las percepciones de algunos expertos en educación, así como de directivos de centros educativos públicos y privados, además de los profesores, acerca de la evaluación docente. Entre los resultados se destaca que los expertos tienen una noción clara acerca de la evaluación docente, así como la utilidad que ésta tiene en la mejora de la calidad educativa. Los expertos y directivos coinciden en que los profesores debieran ser considerados en el diseño e implementación de los procesos de evaluación docente.

La investigación realizada en México es también escasa. No existen estudios específicos de las opiniones de los funcionarios universitarios sobre la evaluación docente. Los trabajos identificados han incluido simultáneamente a funcionarios, profesores o estudiantes. Aquino, Garza, Minami, y Fabila (2006) llevaron a cabo una investigación, acerca de las opiniones que tienen los estudiantes, directivos y profesores sobre la evaluación del desempeño docente. Todos los entrevistados coinciden en que la evaluación tiene que reflejar fines formativos y no de control como se ha venido haciendo. Los entrevistados afirman que el cuestionario de opinión estudiantil, es obsoleto y que se tienen que buscar nuevas maneras de retroalimentar y mejorar la docencia.

Si bien se conoce las opiniones y percepciones de los estudiantes y profesores sobre la evaluación docente, y opiniones generales funcionarios universitarios, no se han realizado estudios específicos en México que den cuenta con más detalle de las opiniones que tienen los funcionarios universitarios sobre la evaluación docente, a pesar de la importancia que tienen las autoridades en la toma de decisiones. 
En relación con los trabajos realizados durante los últimos años que empelan específicamente a las RS como postura teórica y metodológica en torno a la evaluación, se encontraron los siguientes: Nájera y García, (2007), Hernández (2010), Torres, (2013), Mustafá y Ramírez (2014), Bautista y López (2015), Pérez, (2016), Di Franco, (s/f) y Bautista (2016). La mayor parte de estos trabajos se han dedicado a estudiar los procesos de evaluación del profesorado en su práctica educativa, tanto en educación básica como en educación media, en normales y en escuelas rurales. De estos, sólo dos investigaciones se han enfocado en la educación superior, estudios que abordan las RS de docentes y estudiantes acerca de la evaluación del aprendizaje. La búsqueda bibliográfica realizada por los autores de este trabajo no identificó estudios sobre la mirada que los funcionarios universitarios tienen acerca la evaluación, en los que se hayan empleado el enfoque de las representaciones sociales.

Como se ha visto, esta línea de investigación tan poco explorada puede aportar hallazgos que mejoren la implementación de políticas de evaluación del desempeño docente.

El propósito de este trabajo fue investigar las representaciones sociales que tienen los funcionarios universitarios acerca de la evaluación docente. Las preguntas que se tratan de responder en el estudio son: ¿Cuál es la concepción de los funcionarios sobre la evaluación? ¿¿Cuál es su concepción sobre la evaluación docente?

\section{Metodología}

\subsection{Postura teórica- metodológica: Representaciones Sociales}

En virtud de que lo que nos interesa es identificar el punto de vista de las autoridades acerca de la evaluación y la evaluación docente, esta investigación se inscribe en un paradigma cualitativo adscrito a la tradición fenomenológica. Por ello este trabajo retoma la propuesta teórico-metodológica de las representaciones sociales (RS), ya que ésta permite detectar esquemas subjetivos de percepción, de valoración y acción. Por ello el centro de interés lo constituyen las percepciones del sujeto, sus vivencias sobre la evaluación por tanto en esta perspectiva, se privilegia al actor y a su subjetividad.

Las RS son una manifestación del conocimiento de sentido común (Moscovici, 1979), las expresa un actor (Secord, 1989) y se refieren a algo o a alguien (Jodelet, 1986). Son complejas construcciones sociales que condensan imágenes y anhelos de las personas de un grupo, comunidad o sociedad (Jodelet, 1986; Palmonari y Doise, 1986; Rouquette, 2000). Son un cuerpo de conocimientos que permiten hilvanar ideas, clasificar el mundo social y a sus actores, organizar y actuar en el mundo de la vida cotidiana. Es en los pequeños espacios de interacción donde se elaboran las RS a través de la comunicación entablada con los amigos, familiares y, la difusión de imágenes e ideas transmitidas en los medios de comunicación masiva las convierte en sociales (Carugati y Séller, 2000). No son una clasificación fría y objetiva emprendida por quienes observan o analizan algo $o$ a alguien, sino una sustitución en el pensamiento de aquello que se observa o analiza. Las RS no son ajenas a la particularidad social del actor, específicamente, de sus condiciones socioeconómicas y códigos culturales, tales como edad, actividad realizada, información acerca del objeto de representación, entre otras.

Con base en Jodelet (1986), la construcción de las RS tiene autonomía y creatividad. Autonomía, porque cada grupo o comunidad puede colocar el sello específico en la 
representación; creatividad, porque se pueden construir numerosas representaciones de algo o alguien. Las RS no buscan el rigor ni la sistematicidad, incluso pueden diferir de un grupo a otro, en gran parte porque responden a la ubicación social de quienes expresan su posición. Son producto de la vida cotidiana y orientan las acciones de los actores en las actividades diarias, a diferencia del especialista que hace un análisis del proceso y de las prácticas en la vida cotidiana. Incluso, pueden o no coincidir con las metas institucionales o con el perfil que la institución espera de los profesores. Los funcionarios educativos podrán instrumentar en sus microespacios escolares las políticas de corte nacional e institucional, incluso evaluar periódicamente sus alcances, pero la aceptación de éstas estriba de la disposición de los actores (profesores, estudiantes) con base en sus respectivas RS. En otras palabras, las autoridades podrán instrumentar numerosos programas de formación y actualización docente y éstos podrán o no tener impacto en los profesores y en sus prácticas, dependiendo de sus RS: compromiso con la tarea que realizan, el manejo de los contenidos, la disposición para la práctica docente, entre otras. Sin esto, los cursos ofrecidos institucionalmente o en otros espacios académicos, poco impacto pueden tener en los docentes y en sus prácticas.

Con fundamento en lo anterior, se debe señalar que las RS son una forma de conocimiento elaborado en los espacios de interacción cotidiana, nutrido por la información que se expone en los medios de comunicación de masas, heredero de un momento histórico determinado y de la ubicación social del actor en una sociedad jerarquizada. En el caso de la educación superior, los intercambios diarios entre los actores son un terreno fértil para la construcción de RS sobre lo educativo: contenidos, prácticas, agentes, instalaciones, reglamentos, etc. En consecuencia, las RS se enlazan con las prácticas educativas que los agentes instrumentan, dentro de un entorno social y cultural. Reconocer los significados diseñados en los microespacios sociales ha llevado a que esta perspectiva cobre importancia dentro de la investigación educativa en México (Piña y Cuevas, 2004). Cabe mencionar que en esta investigación se decidió abordar las RS de las autoridades universitarias desde el enfoque procesual. Este enfoque es una corriente de investigación iniciada por Jodelet, tiene como objetivo la descripción de las RS, considerando que estas son sistemas de significado en los cuales se hace evidente la interacción que sostienen los grupos y los individuos con el medio (Rateau, 2016) a través del cual se constituyen y se comparten las representaciones.

\subsection{Población participante}

Para llevar a cabo el trabajo de campo se eligió como referente empírico a diez funcionarios de una universidad pública de la Ciudad de México. Esta institución tiene cinco campus, cuatro de esos están localizados en la zona metropolitana. Las autoridades participantes son del plantel sur de esta institución. La población seleccionada fueron diez funcionarios: la Rectora del campus y nueve funcionarios de la División de Diseño, a saber: el director de la División, cuatro jefes de departamento y cuatro coordinadores de las carreras de diseño gráfico, diseño industrial, arquitectura y planeación territorial. Todos ellos, excepto la rectora, son las autoridades que están al frente de dicha División.

\subsection{Instrumentos y técnicas de recolección de datos.}

Esta investigación se llevó a cabo a partir de un enfoque cualitativo, adoptando un diseño exploratorio con una perspectiva descriptiva-interpretativa. Para el acopio de la información se utilizó como herramienta la entrevista en profundidad (Taylor y Bogdan, 
1987). La entrevista es una técnica que requiere de la interacción "cara a cara" con los informantes, esto favorece la recuperación del discurso extenso de los sujetos y la posibilidad de un análisis fino y detallado, no sólo del contenido de la entrevista, sino también de las actitudes, emociones y gesticulación que se evidencia en cada intervención del informante. Por tal motivo ha sido considerada como una herramienta fundamental en la identificación de las RS. En el guión de la entrevista se incluyeron preguntas que no fueran directivas sino preguntas para entablar un diálogo y que el informante se sintiera con la libertad de expresar sus ideas y opiniones libremente. Las preguntas de las entrevistas se formularon a partir de métodos asociativos (Abric, 2004). Estos se centran en una expresión verbal que el investigador trata que sea más espontánea, menos controlada, por ende más auténtica (Gutiérrez y Piña, 2008). Se formularon 13 preguntas que guiaron la entrevista. Estas se agruparon en dos niveles. El primero incluía las opiniones de los entrevistados, acerca de la evaluación en general, es decir cómo la concebían estos actores y cuáles eran sus finalidades. El segundo se abocó a ahondar acerca de la evaluación docente, la forma en que la conceptualizaban los funcionarios, cuáles eran sus principales funciones y si ésta después de más de veinte años de su implementación, había mejorado el trabajo del profesor, entre otras cuestiones más. Las entrevistas fueron realizadas en base a una pauta semiestructurada, que señaló tópicos a conversar, cuidando de no definir conceptos o categorías a priori.

\section{4 Procedimiento}

Se realizaron entrevistas con cada uno de los funcionarios universitarios. La muestra fue seleccionada a priori. Se solicitó una cita con las autoridades de la institución. En esta se les explicó con detalle en qué consistía el trabajo. La entrevista se realizó en la oficina de la autoridad correspondiente. Se sistematizó y analizó la información empírica, para ello se utilizó el análisis de contenido, el cual es una técnica de investigación destinada a formular, a partir de ciertos datos, inferencias reproducibles y válidas, que puedan aplicarse a un contexto (Krippendorf, 1990) y responder al problema de investigación. Con el objeto de facilitar el proceso de análisis se utilizó el programa Atlas-ti. Este es un programa informático que permite al investigador agilizar muchas de las actividades implicadas en el análisis cualitativo y la interpretación. El análisis textual consistió en tomar las respuestas de las autoridades e irlas clasificando de acuerdo a la categoría principal establecida en la guía de entrevista: concepto de evaluación.

\section{Análisis de resultados}

Los hallazgos obtenidos en la investigación se presentan mediante niveles de análisis descriptivos, en categorías y subcategorías que parten de la categoría de análisis y otras se derivaron de la información empírica recopilada. Los resultados son los siguientes:

En relación con la primera pregunta que se les hizo a las autoridades: ¿Qué es lo primero que se le viene a la mente cuándo escucha la palabra evaluación? Los hallazgos obtenidos en el trabajo de campo, dan cuenta de que los funcionarios universitarios tienen clara la conceptualización de lo que es "idealmente" la evaluación. 


\subsection{Concepciones sobre evaluación}

Las RS de la mayor parte de los funcionarios aluden a que la evaluación permite emitir un juicio de valor de la persona que se está evaluando. Lo que permite valorar si ésta ha realizado correctamente las funciones para las que fue contratada.

\subsubsection{Categoría 1. Evaluación: medir el valor de algo o alguien}

Las autoridades entrevistadas, conciben a la evaluación como: una forma de valorar, medir el valor de una persona, de un proceso, de una experiencia educativa, A continuación, se presentan las opiniones que dan cuenta de lo significa la evaluación para estos actores universitarios

La evaluación forma parte de una valoración de algo o de alguien. Esta permite, a quienes realizan la evaluación, contar con elementos claros y suficientes, para determinar el valor de lo que se está evaluando. (ECL) ${ }^{1}$

La evaluación es un corte de caja de las actividades que realiza alguien, para saber cómo se ha desarrollado una situación educativa o programa de estudios. Es decir, al realizar una evaluación, tenemos un parámetro a partir del cual se puede medir, corroborar lo que se evalúa. (EJD) $)^{2}$

Evaluar es emitir un juicio de valor con fundamentos críticos que nos den elementos para juzgar si se están cumpliendo los objetivos propuestos. (EDD) $)^{3}$

Todo esto no quiere decir que los funcionarios sean expertos en evaluación. Más bien sus opiniones al respecto, las han construido en los espacios en donde éstos interactúan cotidianamente con sus colegas y amigos, en la comunicación entablada con otras autoridades, en las discusiones que han sostenido en los diferentes espacios académicos de la institución o fuera de ésta. Así como en la difusión, a la que han tenido acceso, que se ha hecho de esta problemática transmitida en los medios de comunicación masiva. Todo ello convierte a estas opiniones en RS (Carugati y Séller, 2000).

Cuando se interrogó a los funcionarios universitarios acerca de lo que se les venía a la mente cuando escuchaban las palabras: evaluación docente. Los hallazgos obtenidos en el trabajo de campo, dan cuenta de que los funcionarios universitarios no obstante de que, son capaces de expresar con claridad lo que es para ellos la evaluación, cuando se refieren específicamente a la evaluación docente, éstos no aluden al concepto como tal, sino que confunden el termino evaluación docente con los fines que ésta tiene. Por ello, a partir de los resultados del análisis empírico, emergieron categorías y subcategorías que no se tenían contempladas y que tienen que ver con los usos o finalidades de la evaluación.

\subsubsection{Categoría 2. Evaluación docente: encuesta estudiantil}

El análisis del trabajo de campo reveló que una categoría recurrente a la que aluden la mayor parte de las autoridades, es que la evaluación docente tiene que ver con el cuestionario que responden los estudiantes, para evaluar el desempeño de su profesor en

\footnotetext{
${ }_{1}$ Entrevista a coordinador de licenciatura realizada en el año 2016 entre los meses de septiembre a diciembre.

${ }^{2}$ Entrevista a jefe de departamento realizada en el año 2016 entre los meses de septiembre a diciembre.

${ }^{3}$ Entrevista a director de la división realizada en el año 2016 entre los meses de septiembre a diciembre.
} 
el aula. Es decir, para los funcionarios la evaluación es en esencia la aplicación y resultados del cuestionario de evaluación

Para mí la evaluación docente son las encuestas que los alumnos responden para evaluar al profesor. Hay ciertas preguntas que los estudiantes si están capacitados para responder. Por ejemplo, si el profesor asiste o no a las clases. Si presenta su programa docente a tiempo. Sin embargo, hay otras que el estudiante no tiene la capacidad de contestar por más preparado y consciente que esté. El alumno no tiene la capacidad de decidir si yo domino o no un tema. (ECL)

La evaluación docente en esta institución se resume a un cuestionario que tienen que responder los alumnos, en el que se incluyen ciertas preguntas que no necesariamente dan cuenta de lo que aprendió el alumno. (EJD)

Está basada en una larga encuesta con muchas preguntas dirigidas a los alumnos. La mayor parte de estas preguntas homogenizan a la docência. (ER $)^{4}$

El cuestionario estudiantil es un instrumento que ya no cumple la función para la cual fue diseñado, ya está caduco. (JD)

Llama la atención que las autoridades que están a cargo de implementar la evaluación docente, no reconocen la validez del cuestionario de opinión estudiantil, cuando en principio cabría esperar que fueran ellas las que defendieran esta metodología que se emplea para evaluar la docencia, ya que ellas son las encargadas de dirigir las políticas evaluativas en la institución.

a) Evaluación docente: rechazada por los alumnos

Los funcionarios universitarios al referirse al cuestionario de opinión que responden los alumnos, admiten el poco interés de los chicos en evaluar el desempeño de sus profesores. Una de las razones que expresan las autoridades se relaciona con la apatía de los alumnos, lo que tiene que ver, según las opiniones de algunos coordinadores, con el hecho de que estamos ante una evaluación sin consecuencias. Los jóvenes consideran que independientemente de la valoración que hagan del desempeño de sus profesores eso no generará ninguna repercusión o cambio en su docencia.

Este desinterés que tienen los alumnos por evaluar a sus docentes, me parece que ha sido en gran parte porque ellos mismos comprueban trimestre con trimestre que dicha evaluación no se traduce en mejoras en el aula o en sanciones para quienes consideran los alumnos que es un mal profesor. (ECL)

To como coordinador, tengo pedirles a los profesores que les digan a sus alumnos que tienen que permanecer en el aula, cuando llegan los encuestadores para aplicar los cuestionarios. (ECL)

Los alumnos se han venido a quejar conmigo, que ya están hartos de responder el mismo cuestionario seis o siete veces cada trimestre, porque como tu bien sabes en Diseño Gráfico imparten el mismo módulo hasta siete profesores. (ECL)

Algunos docentes me han comentado que el día en que se aplicará la encuesta, les tiene que decir a los alumnos que todos tienen que asistir a clases porque la temática que van a tratar es de suma importancia. (ECL)

Probablemente esta falta de credibilidad en los resultados de la evaluación docente a la que aluden las autoridades explica, al menos en parte, el hartazgo que los estudiantes

\footnotetext{
${ }^{4}$ Entrevista realizada a la rectora de este campus, en el año 2016 entre los meses de septiembre a diciembre.
} 
presentan para responder el cuestionario, lo cual revela el agotamiento y la inoperancia de esta política de evaluación.

\section{b) Evaluación docente: remuneración económica, simulación}

Las autoridades, sin importar el cargo que ocupan en la institución, coinciden también que la evaluación docente ha servido básicamente para otorgar una remuneración económica al profesor que ha sido bien evaluado por sus estudiantes.

Los cuestionarios de evaluación estudiantil, no funcionan más que para otorgar una beca al "buen" profesor. (EJD)

La evaluación docente sirve para establecer parámetros que indiquen a los diferentes órganos colegiados, si a un profesor se le va dar o no la beca al reconocimiento a la carrera docente. Es para lo único que ha servido. (ER)

Esta evaluación está muy devaluada, puesto que sólo ha servido para negociar las horas de docencia que ha acumulado un profesor y con ello obtener una beca. (ED)

To le he dicho personalmente al director de la División: oye para que nos pones a llenar estas evaluaciones si no sirven para nada. Sería mejor darles la beca a todos los docentes y nos quitamos de simulaciones. (ECL)

\section{c) Evaluación docente: rutina}

Las representaciones sociales de las autoridades, en su mayoría concuerdan en que la evaluación únicamente ha servido como un trámite burocrático en todos los niveles: para los estudiantes, para los jefes y para los coordinadores, sin que ésta haya servido para mejorar la docencia, es decir que la evaluación no se ha empleado para fines formativos.

Una rutina que todos tenemos que llevar a cabo cada trimestre: jefes, alumnos y coordinadores. (EJD)

La evaluación docente tiene un costo muy elevado. Ta que genera, papel, pago de encuestadores, muchas horas de trabajo y todo esto no repercute en mejorar la docencia. (EJD)

Se realiza la evaluación nada más para cumplir con el requisito. Esta es una rutina, que se lleva a cabo cada trimestre. (ECL)

Parece ser que la razón principal que justifica la existencia, desde hace más de veinte años, de la evaluación es el cumplimiento de una demanda administrativa por parte de instancias tanto internas como externas.

\subsubsection{Categoría 3. Evaluación docente: aprendizaje de los estudiantes}

Otra categoría que emergió en el análisis del trabajo de campo, tiene que ver con que algunas de las autoridades confundieron a la evaluación docente, con la evaluación del aprendizaje de los estudiantes. Cabe mencionar que esta visión de aprendizaje también está vinculada con el uso sumativo de la evaluación. Los siguientes testimonios dan cuenta de ello.

Es el juicio y la razón de verificar que los alumnos hayan aprendido. (ECL)

La evaluación de la docencia es saber qué está haciendo el docente en el aula, y conocer si éste realmente logró que los estudiantes aprendieran. (EJD)

Conocer a partir de los resultados del aprendizaje de los alumnos, si el profesor logró cumplir los objetivos del curso. (ER)

Evaluar los resultados del aprendizaje de los alumnos (ED) 


\section{Discusión y Conclusiones}

\subsection{Discusión}

El propósito de este trabajo fue investigar las representaciones sociales que tienen los funcionarios universitarios acerca de la evaluación y de la evaluación docente. Para llevar a cabo la investigación se recurrió al marco teórico metodológico de las representaciones sociales (RS). Las RS se construyen a partir de las experiencias de las personas, mediante las interacciones que establecen entre ellas, por medio del diálogo que llevan a cabo, y a través de la información que les llega inclusive de los medios de comunicación. Dicho enfoque permite comprender tanto la subjetividad de cada individuo como la de los integrantes de una comunidad o grupo social. En este caso se buscó identificar las RS que los funcionarios universitarios han construido acerca de la evaluación y de la evaluación docente.

Llama la atención que los funcionarios se muestran críticos con las prácticas de evaluación docente que imperan en la institución, pero en el ejercicio de su función como autoridad, no han hecho mucho para cambiar este estado de cosas con el que declaran estar en desacuerdo. Los entrevistados no formularon una propuesta o iniciativa concreta para analizar, debatir y, en su caso cambiar, el proceso de evaluación docente que existe en la institución. La evaluación docente parece un mal necesario del que no se desea prescindir, quizá por los beneficios que conlleva para todos. No obstante, hay que reconocer que la decisión de modificar la política de evaluación de la docencia en la institución va más allá de las atribuciones que los funcionarios universitarios tienen. A partir de los programas de estímulos o mérito que se iniciaron a principios de la década de los 90 del siglo pasado, se generalizó en las universidades públicas mexicanas el uso de los resultados de la evaluación en el otorgamiento de estímulos económicos a los profesores.

Por otro lado, de acuerdo con los resultados obtenidos, se reconocieron coincidencias entre lo que han informado otros investigadores acerca de esta temática y los resultados de la presente investigación. Entre las principales semejanzas se identificó que las opiniones de los funcionarios universitarios y los resultados de otros estudios realizados anteriormente, coinciden en que la evaluación no ha sido útil para mejorar la docencia, que su único fin ha sido otorgarle al profesor una remuneración económica (Zúñiga y Joipa, 2007). Entre las diferencias encontradas en este estudio y los demás investigaciones citadas y revisadas en el estado del arte, en relación a que algunas autoridades opinan que los usos de la evaluación son formativos, mientras que otras le asignan usos sumativos (Perassi, 2008). En esta investigación las RS de las autoridades universitarias, todas coinciden que la evaluación se emplea con fines sumativos.

Se encontró también que las opiniones de los funcionarios universitarios, vertidas en este trabajo, no reflejan una concepción clara de evaluación docente, a diferencia de otras investigaciones que señalan que los directivos estudiados, tienen claridad en torno a la concepción de evaluación docente, así como a la utilidad que ésta tiene en la mejora de la calidad educativa (Coloma, 2010).

Estamos de acuerdo con Aquino et al. (2006) en que la evaluación debería reflejar fines formativos y no de control, además, que el cuestionario de opinión estudiantil es obsoleto, por tanto, se sugiere modificarse de suerte que responda mejor a las nuevas 
realidades y complejidades de la enseñanza universitaria (Moreno, 2009). También es necesario realizar más investigaciones de este tipo que busquen nuevas maneras de retroalimentar y mejorar la docencia universitaria.

A pesar de que la evaluación docente es diferente a la evaluación del aprendizaje, nos parecen oportunas las opiniones que expresan las autoridades entrevistadas, respecto a que la evaluación tendría que servir para conocer si los alumnos aprendieron los conocimientos que el profesor les impartió en el curso. Ya que se ha constatado que el cuestionario de opinión estudiantil que se aplica en la institución objeto del estudio para evaluar a los docentes, no contiene una sola pregunta o enunciado que permita poder confirmar si hubo o no aprendizaje por parte de los estudiantes (Arbesú, 2006). Por tanto, sería necesario incluir uno o varios ítems que dieran razón de lo anterior.

Estas declaraciones también revelan cómo a través de los resultados de aprendizaje de los alumnos, las autoridades evalúan la calidad de la enseñanza, digamos que es una forma indirecta de valorar el desempeño del profesor. Aunque establecer esta relación es un tanto problemática porque sabemos que las posibilidades de aprendizaje del alumno en una asignatura o curso está influido o condicionado por múltiples factores, entre los cuales se encuentra la enseñanza del profesor, pero no exclusivamente.

Todos estos testimonios nos permiten considerar que las RS que tienen las autoridades de la evaluación docente más que ofrecer una concepción clara de ésta, la entienden a partir las finalidades o usos que se le asignan. Las autoridades entrevistadas se identificaron con el uso sumativo de la evaluación y no con el uso formativo. Debido a que en sus relatos no aparece que la evaluación docente se utilice para conocer las fortalezas y debilidades de la docencia, con la finalidad de ayudar a los profesores a mejorar su trabajo diario.

\subsection{Conclusiones y recomendaciones}

Se puede concluir que los funcionarios universitarios de esta institución tienen clara la concepción "ideal" de evaluación. No obstante, éstas mismas autoridades no tienen una representación clara de la evaluación docente; más bien han logrado identificar los distintos usos que a ésta se le atribuyen, algunos de los cuales parecen bastante alejados de la finalidad para la cual fue creada la evaluación docente en sus orígenes, hace ya algunas décadas, la cual es de naturaleza formativa, más que sumativa. Los usos que las autoridades entrevistadas le han otorgado a la evaluación docente son sumativos, debido a que en sus opiniones los funcionarios, destacan que la evaluación del profesor tiene como propósito determinar niveles de rendimiento, decidir si se produce el éxito o el fracaso. Hacen referencia al juicio final global de un proceso que ha concluido y sobre el que se emite una valoración terminal, en este caso valoración del trabajo del profesor en el aula.

Es importante enfatizar también que no hubo diferencias en las RS de los funcionarios, sobre lo que es la evaluación docente, aunque se tratara de una rectora de Unidad, un director de división, jefes de departamento o coordinadores de licenciatura En este sentido, se podría afirmar que las autoridades, independientemente del cargo que ocupan en la estructura universitaria, parecen compartir una misma visión respecto de la evaluación docente, con algunos matices claro está, lo que en alguna medida perfila el peso de una cierta cultura de evaluación dominante. 
Los propios funcionarios universitarios no creen en las supuestas bondades de la evaluación docente, aunque ellos mismos sean responsables de ponerla en marcha; al menos en la división de ciencias y artes para el diseño, así lo revelan sus severas críticas a los usos sumativos que hasta hoy se le ha venido dando a la evaluación docente, particularmente mediante el cuestionario de opinión estudiantil. En las representaciones sociales de los funcionarios universitarios se identifica el predominio de una perspectiva técnica de la evaluación docente por encima de otras perspectivas teóricas, pareciera que algunas autoridades se sienten más seguras con una forma de evaluación que alude más a lo técnico. Esto debería conducirnos a replantear la continuidad de este tipo de instrumentos que no justifican el enorme gasto (dinero, tiempo, energías...) que representa su aplicación. Parece ser que la razón principal que justifica su existencia es el cumplimiento de una demanda administrativa por parte de instancias tanto internas como externas.

Todo ello da cuenta de que una evaluación, al menos en el discurso oficial, que originalmente fue pensada para la mejora de docencia, vemos como después de más de veinte años de su implementación ha perdido su esencia, aunque quizá desde su génesis, al estar vinculados sus resultados con el ofrecimiento de estímulos económicos al profesorado, la evaluación ya se hallaba desvirtuada.

Se sugiere que los responsables de la elaboración de las políticas de evaluación docente diseñen un sistema integral de evaluación de la docencia, ya que lo que hasta ahora se tiene en la mayoría las universidades mexicanas, son encuestas de opinión estudiantil y cuestionarios que responden los jefes de departamento y coordinadores de licenciatura para valorar el trabajo del profesor. Esto no constituye un sistema de evaluación, sino que más bien representa el diseño e implementación aislado de ciertos instrumentos que permiten medir algunos aspectos o dimensiones el desempeño del profesor en el aula de clases. Los que nos dedicamos a investigar sobre la evaluación de la docencia consideramos que sería necesario que la evaluación del desempeño docente, se realice mediante diferentes fuentes de información, sin embargo, hay limitadas experiencias de su uso en el caso mexicano.

Una de las limitaciones que tiene este trabajo es que sólo se entrevistó a los funcionarios de la división de ciencias y artes para el diseño y a la rectora de Unidad. Pensamos qué en futuro, sería importante incluir las RS sobre la evaluación de la docencia de las demás autoridades que forman parte de las otras dos Divisiones (ciencias sociales y humanidades; y ciencias biológicas y de la salud) que tiene la institución universitaria objeto de estudio. Otra limitante es que también se tendría que contemplar la opinión de los docentes acerca de la evaluación, ya que ellos son los directamente afectados por este proceso evaluativo. Asimismo, sería importante incluir las RS de los estudiantes sobre esta temática, ya que como vimos en algunos ejemplos, según la opinión de algunas autoridades, éstos consideran poco seria e inútil la evaluación que tienen que responder para valorar el trabajo de sus profesores.

Consideramos que sería importante continuar con esta línea de investigación tan poco explorada, ya que ésta podría aportar hallazgos que permitieran a las autoridades mejorar la implementación de políticas de evaluación del desempeño docente. 


\section{Referencias}

Abric, J. C. (2004). Las representaciones sociales. Aspectos teóricos y Metodología de recolección de las representaciones sociales. En J. C. Abric (Dir.). Prácticas sociales y representaciones (pp. 11-32 y 53-74). Ciudad de México: Ediciones Coyoacán.

Aquino, S., Garza, G., Minami, H. y Fabila, A. (2006). Evaluación al Desempeño Docente: Percepción de docentes, alumnos y administrativos de la DAEA, Memorias de la Semana de divulgación y video científico: Universidad Juárez Autónoma de Tabasco, México.

Arbesú, M. I. (2006). La práctica de la docencia modular: El caso de la Unidad Xochimilco en la Universidad Autónoma Metropolitana. Ciudad de México: UAM/Plaza y Valdés.

Arbesú, M. I., Moreno, T., Comas, O y Contreras, G. (en prensa). El uso de los resultados de la evaluación docente. En E. Luna y M. Rueda (Coords.), Experiencias de evaluación de la docencia en Iberoamérica.

Bautista, N.P. (2016). Problemas éticos y representaciones sociales de la evaluación en la universidad. Revista Iberoamericana de Evaluación Educativa, 9(1), 127-144.

https://doi.org/10.15366/riee2016.9.1.008

Bautista-Cárdenas, N. P. y López-Fúquene, L. (2015). Representaciones sociales, discursos y prácticas sobre los procesos de evaluación en Psicología en la Universidad Cooperativa de Colombia (Documento de trabajo No. 12). Bogotá: Ediciones Universidad Cooperativa de Colombia. https://doi.org/10.16925/greylit.1314

Carugati, F. y Séller, P. (2000). Représentations sociales et education. Montreal: Éditions Nouvelles.

Coloma, C. R. (2010). Estudio comprensivo sobre la evaluación docente, Revista Iberoamericana de Evaluación Educativa, 3(1e), 61-76.

Di Franco, M. G. (s/f). Representaciones docentes en la evaluación escolar. Tesis de máster. Universidad Nacional De La Pampa. Facultad De Ciencias Humanas, Tesis de maestría. Argentina. Recuperado de:

http://www.biblioteca.unlpam.edu.ar/pubpdf/praxis/n14a16difranco.pdf

García Garduño, J. M. (2000). Las dimensiones de la efectividad docente, validez y confiabilidad de los cuestionarios de evaluación de la docencia: síntesis de investigación internacional. En M. Rueda y F. Díaz-Barriga (Comp.), Evaluación de la docencia (pp. 41-62). Ciudad de México: Paidós.

García Garduño, J. M. (2008). El proceso perverso de la evaluación de la docencia en las universidades: Un balance inicial y apuntes para mejorarlo. Revista Reencuentro 53, 9-19.

García Garduño, J.M. (2014). ¿Para qué sirve la evaluación de la docencia? Un estudio exploratorio de las creencias de los estudiantes universitarios. Archivos Analíticos de Políticas Educativas, 22(15), 1-24. https://doi.org/10.14507/epaa.v22n 15.2014

Gutiérrez, S. y Piña, J. M. (2008). Representaciones sociales: teoría y método. En M. I. Arbesú, S. Gutiérrez y J. M. Piña (Coords.), Educación superior. Representaciones sociales (pp. 13-48). Ciudad de México: Gernika.

Hernández, S. (2010). Representaciones sociales sobre el programa de carrera magisterial. Asociación de Entidades Educativas Privadas Argentinas. Recuperado de http://www.adeepra.org.ar/congresos/Congreso\%20IBEROAMERICANO/EVALUACI ON/R1742b_Hernandez.pdf

Ibarra, E. y Porter, L. (2007). El debate sobre la evaluación: Del homo academicus al homoeconomicus. Reencuentro, 48, 34-39. 
Jodelet, D. (1986). La representación social: fenómenos, concepto y teoría. En S. Moscovici (Ed.), Psicología social ll, Pensamiento y vida social. Psicología social y problemas sociales (pp. 469494). Barcelona: Paidós.

Krippendorf, K. (1990). Metodología de análisis de contenido. Buenos Aires: Paidós.

Moreno, T. (2009). La enseñanza universitaria: una tarea compleja. Revista de la Educación Superior, 38(131), 115-138.

Moscovici, S. (1979). El psicoanálisis, su imagen y su público. Buenos Aires: Huemul.

Mustafá, J. E. y Ramírez, G. A. (2014). Las representaciones sociales de las prácticas evaluativas en la educación rural. Colombia: Recuperado de http://repository.usta.edu.co/bitstream/handle/11634/3551/Mustafajorge2014.pdf?sequ ence $=1$

Nájera, F. y García, M. A. (2007). Las representaciones sociales de los profesores sobre los procesos de la evaluación de la práctica docente en la Escuela Normal de los Reyes Acaquilpan. IX Congreso Nacional de Investigación Educativa. México: Consejo Mexicano de Investigación Educativa. Recuperado de: http://www.comie.org.mx/congreso/memoriaelectronica/v09/ponencias/at14/PRE1178 766119.pdf

Palmonari, A. y Doise, W. (1986). Caractéristiques des représentations sociales. En W. Doise y A. Palmonari (Eds.), L’étude des représentations sociales (12-33). Paris: Delachaux \& Niestlé.

Perassi, Z. (2008). La evaluación en educación: un campo de controversias. Laboratorio de Alternativas Educativas, Recuperado de http://lae.unsl.edu.ar/Ediciones/Libros_Electronicos/Libro_La_Eval_En_Educacion.pdf

Pérez, G. M. (2016). La evaluación en la reforma educativa de 2013: una política en un espacio de tensiones y diferencias. Debates en Evaluación y Currículum, 2, 3824-3834. Recuperado de http://posgradoeducacionuatx.org/pdf2016/Fo10.pdf

Piña, J. M. y Cuevas, Y. (2004). La teoría de las representaciones sociales. Su uso en la investigación educativa en México. Perfiles Educativos, 26(105-106), 102-124.

Rateau, J. (2016). Representaciones sociales. El estudio de las representaciones sociales: perspectivas metodológicas. En P. Ducoing (Coord.), La Investigación en educación: epistemología y metodologías (pp. 90-114). Ciudad de México: Plaza y Valdés.

Rouquette, M. L. (2000). Représentations et pratiques sociales: une analyse théorique. En A. Garnier y L. Rouquette (Eds.), Représentations sociales et education (pp. 133-141). Montreal: Éditions Nouvelles.

Rueda, M., Luna, E., García Cabrero, B. y Loredo, J. (2010). La evaluación de la docencia en las universidades públicas mexicanas: Un diagnóstico para su comprensión y mejora. Revista Iberoamericana de Evaluación Educativa, 3(1e), 77-92.

Secord, P. F. (1989). ¿Cómo resolver la dialéctica actor/sujeto en la investigación psicosocial? En T. Ibañez (Coord.), El conocimiento de la realidad social (pp. 13-37). Barcelona: Sendai.

Silva Montes C. (2009) Las encuestas de opinión en la Universidad Autónoma de Ciudad Juárez: ¿Un caso de exclusión del profesorado?. Archivos Analíticos de Políticas Educativas, $17(24)$, $2-35$.

Taylor, S. y Bogdan, R. (1987). Introducción a los métodos cualitativos de investigación. Barcelona: Paidós. 
Torres, A. M. (2013). Representaciones sociales sobre el proceso evaluación desde la mirada de docentes de 10 Año Básico en establecimientos municipalizados urbanos de la comuna de Quilpué. Estudios Pedagógicos, 39, 285-304.

Zúñiga, M., Joipa, B. (2007). La Evaluación del desempeño docente en las Universidades Chilenas: Diagnóstico desde la perspectiva de las autoridades universitarias. En Mineduc (Ed.), Evaluación del desempeño docente y calidad de la docencia universitaria (pp. 35-56). Santiago de Chile: Centro Interuniversitario de Desarrollo.

\section{Breve CV de los autores}

\section{María Isabel Arbesú García}

Doctora en Educación. Profesora titular de la Universidad Autónoma Metropolitana. Integrante: Red de Investigadores sobre evaluación de la docencia. Red Iberoamericana de Investigadores sobre evaluación de la docencia. Observatorio sobre la Didáctica de las Artes, Universidad de Barcelona. Investigadora Nacional por CONACYT. Áreas de investigación y docencia vinculadas con el análisis y la evaluación de la docencia y la enseñanza en educación superior y con el estudio de las representaciones sociales. Como investigadora intenta contribuir a la discusión sobre los problemas que enfrenta la evaluación de la docencia, así como mostrar la complejidad que implica el trabajo pedagógico con la intención de colaborar en la profesionalización de la enseñanza y del aprendizaje en la universidad. Email: isabel.arbesu@gmail.com

\section{José María García Garduño}

Licenciado en Psicología Clínica, Universidad Iberoamericana; Maestría en Educación, Universidad Iberoamericana; Maestría en Administración Educativa, State University of New York-Albany; Doctorado en Educación, Ohio University. Actualmente es profesor a tiempo completo en la Universidad Autónoma de la Ciudad de México. Ha sido profesor de tiempo completo en las universidades: Iberoamericana de la Ciudad de México, Autónoma de Estado de Morelos, Autónoma de Baja California, Autónoma del Estado de Hidalgo y Pedagógica Nacional (Ajusco). Sus intereses de investigación están relacionados con la evaluación de la docencia, teoría del curriculum y administración y gestión escolar. ORCID ID: O000-0002-0955-0880. Email: josemariagarduno@yahoo.com.mx 